\title{
A Case Report on Idiopathic Hypereosinophilic Syndrome
}

\author{
Azad MAK ${ }^{\mathrm{a}}$, Alam A ${ }^{\mathrm{b}}$, Kulsum Uc, Rakib KHB ${ }^{\mathrm{d}}$, Rahman MA ${ }^{\mathrm{e}}$, Quayum $\mathrm{SL}^{\mathrm{f}}$

\begin{abstract}
Idiopathic hypereosinophilic syndrome is characterized by prolonged peripheral blood eosinophilia neither clonal nor secondary to an identifiable cause and eosinophil mediated organ dysfunction, most frequently involving the heart, the central or peripheral nervous system and the lungs. Here, we report a 22-year-old woman who presented with severe abdominal pain due to pancreatitis. On subsequent work-up, she was found to have idiopathic hypereosinophilic syndrome. It is an unusual presentation of idiopathic hypereosinophilic syndrome, which prompted to report this case.
\end{abstract}

Key words: Idiopathic hypereosinophilic syndrome, pancreatitis, ascites.

(BIRDEM Med J 2018; 8(3): 260-262)

\section{Introduction}

Hypereosinophilia refers to persistent eosinophilia of $>1,500 / \mathrm{mm}^{3}$ of blood for more than six months. Hypereosinophilic syndrome (HES) refers to hypereosinophilia associated with eosinophilmediated organ damage. 'Eosinophil-mediated organ damage includes cardiomyopathy, endomyocardial fibrosis, cutaneous lesions, sinusitis, pneumonitis, neuritis, gastroenteritis and vasculitis. ${ }^{2,3}$ In addition, there are few case reports on eosinophilic pancreatitis, ascites, thromboembolic complications, hepatosplenomegaly. ${ }^{4}$ Secondary eosinophilia is the most frequent cause of peripheral blood eosinophilia. Primary eosinophilia is either clonal or idiopathic/ unexplained. Idiopathic HES is considered when both secondary and clonal eosinophilia is ruled out as a possibility. ${ }^{1}$

Author Information
a. MAK Azad, Professor, Department of Medicine, BSMMU,
Dhaka, Bangladesh.
b. Afroja Alam, Associate Professor, Department of Medicine,
BSMMU, Dhaka, Bangladesh.
c. Umme Kulsum, Phase-A Resident, Cardiology, BSMMU.
d. Kabirul Hasan Bin Rakib, MD Final part student, Department
of Medicine, BSMMU.
e. Md. Atikur Rahman, Phase-B Resident, Internal Medicine,
BSMMU.
f. Shaheen Lipika Quayum, Professor of Pharmacology, Popular
Medical College, Bangladesh.
Address of correspondence: MAK Azad, Professor, Department of Address of correspondence: MAK Azad, Professor, Department of
Medicine, BSMMU, Dhaka, Bangladesh. Email: drazad1971 @gmail.com

Received: March 14, 2018

Accepted: June 30, 2018

\section{Case Report}

A 22-year old woman presented with 7-day history of sudden onset severe epigastric pain which was constant, aggravated by taking food and radiating to back. Pain was associated with nausea and several episodes of vomiting and managed conservatively. After few days she noticed gradual abdominal distension without pedal edema or facial puffiness. She had no history of joint pain, oral ulcer, skin rash, fever or weight loss.

She had similar type of pain 1 year back. She had recurrent sinusitis and chronic non productive cough for 3 years. She had no family history of atopy or such illness. Her previous CBC revealed total count 22,490/ $\mathrm{mm}^{3}$ with $51 \%$ eosinophils (AEC-11,470/ $\mathrm{mm}^{3}$ ).

On examination, her pulse was $110 / \mathrm{min}$ regular, blood pressure 110/70 mm Hg, non-icteric, non-oedematous, JVP was not raised. Abdomen examination revealed ascites with no organomegaly. Examination of other systems revealed only right sided pleural effusion. A clinical diagnosis of acute pancreatitis with ascites and right sided pleural effusion was made.

$\mathrm{CBC}$ revealed $\mathrm{Hb} 13.7 \mathrm{gm} / \mathrm{dl}$, TLC $25,000 / \mathrm{mm}^{3}$ with $40 \%$ eosinophil. Serum amylase and lipase done on $7^{\text {th }}$ day of abdominal pain was normal. Urine amylase was $760 \mathrm{U} / \mathrm{L}$ (normal < $360 \mathrm{U} / \mathrm{L}$ ). Her serum calcium, albumin, SGPT, creatinine, electrolytes, sugar and lipid profile were normal. CRP was $14.43 \mathrm{mg} / \mathrm{L}$. CXR revealed bilateral pleural effusion (fig.1). Abdominal sonography revealed only moderate ascites \& bilateral pleural effusion (fig.2). Ascitic fluid was straw coloured and study revealed total count $9000 / \mathrm{mm}^{3},(95 \%$ 
neutrophil, 5\% lymphocyte, no malignant cell), albumin $27 \mathrm{gm} / \mathrm{L}$, SAAG $7 \mathrm{gm} / \mathrm{L}$ and normal glucose, ADA, amylase level.

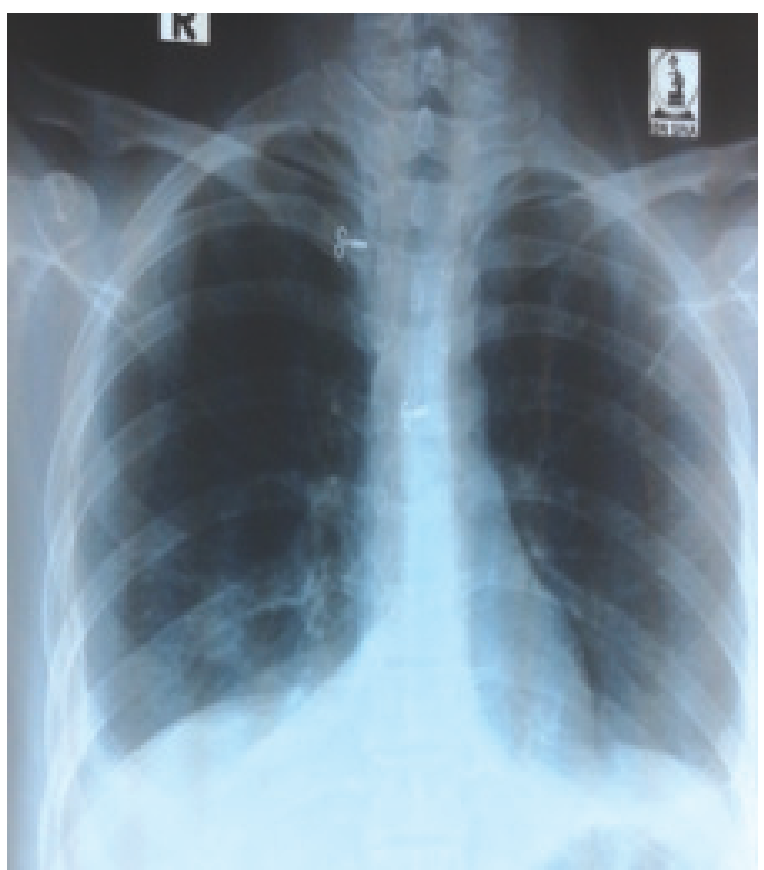

Figure $1 \mathrm{X}$-ray Chest PA view showing bilateral pleural effusion
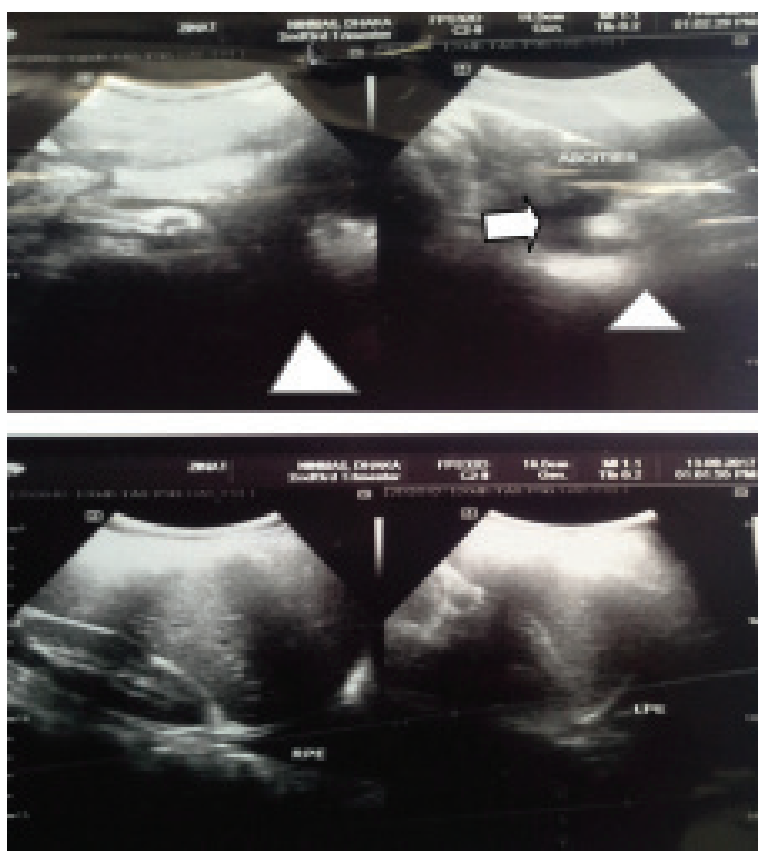

Figure 2 Ultrasonoraphy of whole abdomen showing ascites (arrow) and bilateral pleural effusion (arrowheads)
ANA, Anti-ds-DNA, c-ANCA, p-ANCA, hepatitis viral markers were negative. Urine R/E and Stool R/E were normal, and ICT for filaria was negative. Serum IgE was $2611.31 \mathrm{IU} / \mathrm{ml}$ (adult $<100 \mathrm{IU} / \mathrm{ml}$ ). CT scan of abdomen with contrast showed huge ascites with bilateral pleural effusion, pancreas normal in morphology, mostly uniform mild thickening of gastric antrum and mild thickening of anti-mesenteric wall of the dilated intestinal coils - possibly gastritis and enterocolitis (fig 3). Endoscopy of upper GIT and Echocardiography were normal.

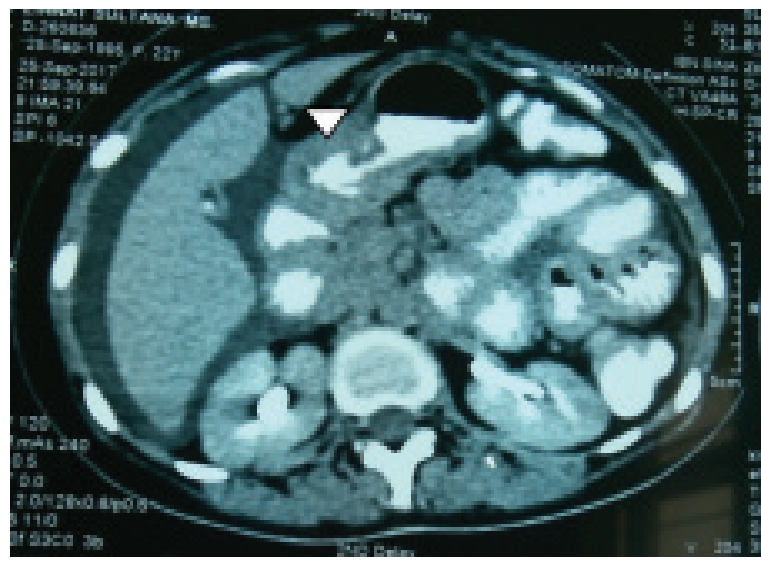

Figire $3 \mathrm{CT}$ scan of abdomen with contrast showed huge ascites, mild thickening of gastric antrum (arrowhead) and mild thickening of anti-mesenteric wall of dilated intestinal coils (arrow)

Bone marrow study showed hyperactive granulopoiesis, shift to left, predominant eosinophilic myelocyte, no evidence of malignancy or parasitic infestation. Bone marrow cytogenetic study including BCR-ABL gene product were negative. FISH (fluorescence in situ hybridization) showed negative for PDGFR beta gene rearrangement or 5q32-33; negative FIP1L1-PDGFR alpha gene rearrangement or $4 q 12$ (found in chronic eosinophilic leukemia). As neither secondary nor clonal cause was found, this case was diagnosed as an idiopathic hypereosinophilic syndrome. She was treated with tablet prednisolone $40 \mathrm{mg}$ daily for 2 weeks then gradually tapered. Patient's condition improved with decreasing abdominal pain, vomiting and ascites. CBC was done after 2 days of starting of prednisolone showed normal total WBC count $\left(10,000 / \mathrm{mm}^{3}\right)$ with $1 \%$ eosinophil (AEC-90/ $\mathrm{mm}^{3}$ ). Ultrasound of abdomen after 1 week revealed no ascites. 


\section{Discussion}

Primary eosinophilia is classified as clonal or idiopathic. Diagnosis of clonal eosinophilia requires morphologic, cytogenetic or molecular evidence of a myeloid neoplasm. Examples of clonal eosinophilia include eosinophilia associated with acute myeloid leukemia, MDS, CML, mastocytosis. Myeloid neoplasmassociated eosinophilia also includes the WHO MPN subcategory of chronic eosinophilic leukaemia, not otherwise specified (CEL-NOS). ${ }^{1}$

Idiopathic Hypereosinophilic Syndrome (HES) is diagnosed when both secondary and clonal eosinophilia are ruled out as a possibility. ${ }^{2}$ The symptoms are variable and related to the organs involved.The common organ systems involved are hematologic (100\%), cardiovascular $(58 \%)$, cutaneous $(56 \%)$, neurologic $(54 \%)$, pulmonary $(49 \%)$, splenic $(43 \%)$, hepatic $(30 \%)$, ocular $(23 \%)$, gastrointestinal $(23 \%) .{ }^{4}$ Gastrointestinal tract involvement can accompany HES and $20 \%$ of patients at some time may have diarrhea. $5,6,7$ Eosinophilic gastritis, enterocolitis, or colitis may be present. ${ }^{8-11}$ Pancreatitis and sclerosing cholangitis occur rarely. ${ }^{7,8}$ Hepatic involvement with HES includes chronic active hepatitis ${ }^{12,13}$ and the Budd-Chiari syndrome from hepatic vein obstruction. ${ }^{14}$ In this case there is hematological, pulmonary, pancreatic, ascites and gastrointestinal tract involvement.

Idiopathic HES is a diagnosis by exclusion, thus all other possible causes of eosinophilia have to be ruled out before making a certain diagnosis. The diagnostic workup must include peripheral blood screening for mutation of FIP1L1-PDGFRA (alpha) and PDGFRB (beta) mutations using fluorescence in situ hybridization (FISH). This is crucial before diagnosis of idiopathic HES because clonal eosinophilia is easily treated with imatinib. If mutations are negative bone marrow examination for cytogenetic studies is indicated to rule out other myeloid malignancy. ${ }^{1}$

Glucocorticoids are the cornerstone of therapy in idiopathic HES. Treatment with oral prednisolone is usually started at $1 \mathrm{mg} / \mathrm{kg}$ per day and continued for $1-2$ weeks before the dose is tapered slowly over the ensuing 2-3 months. If symptoms recur at a prednisolone dose level of $>10 \mathrm{mg} /$ day, either hydroxyurea or interferon alpha is used as steroid-sparing agent.In patients who do not respond to usual therapy as outlined above, mepolizumab, alemtuzumab might be considered. Mepolizumab targets interlukin-5 (IL-5), a well recognizd survival factor for eosinophils. Alemtuzumab targets the CD52 antigen, which has been shown to be expressed by eosinophils but not by neutrophils. ${ }^{1}$

\section{Conclusion}

Persistent peripheral blood eosinophilia demands further evaluation to diagnose the underlying cause and to identify eosinophil-mediated organ damage. Our patient had eosinophilia for more than 1 year and presented to us with a very unusual organ involvement i.e. pancreatitis with ascites. High index of suspicion is required for early diagnosis and treatment, by which we can reduce morbidity and mortality.

Conflict of interest: Nothing to declare.

\section{References}

1. Kasper DL, Hauser SL, Jameson JL, Fauci AS, Lungo DL, Loscalzo J, editors.Harrison's principles of internal medicine. $19^{\text {th }}$ edition.McGraw Hill education 2015,p.135e 7-8.

2. Karnak D, Beders K, Delibalta M. Hypereosinophilic syndrome with pulmonary and cardiac involvement in a patient with asthma. JAMC 2003; 168: 172-75.

3. Hardy WR, Anderson RE. The hypereosinophilic syndrome.Ann Intern Med 1968;68:1220-29.

4. Weller PF, Bubley GJ. The Idiopathic Hypereosinophilic Syndrome. Blood 1994;83:2759-79.

5. Chusid MJ, Dale DC, West BC, Wolff S. The hypereosinophilic syndrome. Analysis of fourteen cases with review of the literature. Medicine (Baltimore) 1975; 54: 1.

6. Spry CJ, Davies J, Tai PC, Olsen EG, Oakley CM,et al. Clinical features of fifteen patients with the hypereosinophilic syndrome. Q J Med 1983; 52: 1.

7. Pancreatic involvement, ascites and diarrhea in idiopathic hypereosinophilic syndrome. Bellaiche G, Fontaine H, Choudat L, Lusiana D, Ley G, Slama JL. Gastroenterol Clin Biol 1997; 21: 619-22.

8. Scheurlen M, Mork H, Weber P. Hypereosinophilic syndrome resembling chronic inflammatory bowel disease with primary sclerosing cholangitis. J Clin Gastroenterol 1992; 14:59.

9. Shah AM, Joglekar M. Eosinophilic colitis as a complication of the hypereosinophilic syndrome. Postgrad Med J 1987;63:485.

10. Vandewiele IA, Maeyaert BM, Van Cutsem ET, Geboes KR, Knockaert DC. Massive eosinophilic ascites. Differential diagnosis between idiopathic hypereosinophilic syndrome and eosinophilic gastroenteritis. Acta Clin Belg 1991; 46: 37.

11. Falade AG, Darbyshire PJ, Raafat F, Booth IW. Hypereosinophilic syndrome in childhood appearing as inflammatory bowel disease. J Pediatr Gastroenterol Nutr1991;12:276.

12. Croffy B, Kopelman R, Kaplan M. Hypereosinophilic syndrome. Association with chronic active hepatitis. Dig Dis Sci 1988; 33: 233.

13. Foong A, Scholes JV, Gleich GJ, Kephart GM, Holt PR. Eosinophil-induced chronic active hepatitis in the idiopathic hypereosinophilic syndrome. Hepatology 1991; 13: 1090.

14. Elouaer BL, Zafrani ES, Farcet JP, Saint, Marc GM, Mathieu $D$, et al. Hepatic vein obstruction in idiopathic hypereosinophilic syndrome. Arch Intern Med 1985; 145: 751. 